\title{
A SITUAÇÃO DOS APÁTRIDAS NA NOVA LEI DE MIGRAÇÃO BRASILEIRA: DIÁLOGOS COM OS PRINCÍPIOS DA DIGNIDADE DA PESSOA HUMANA E DA FRATERNIDADE
}

\author{
Deilton Ribeiro Brasil ${ }^{1}$ \\ Tatiane Gonçalves Mendes Faria ${ }^{2}$
}

\section{RESUMO:}

O objetivo do presente artigo é analisar a situação jurídica dos apátridas em face da Lei $\mathrm{n}^{\circ} 13.445 / 17$ ao mesmo tempo em que investiga qual a efetiva contribuição para a garantia dos direitos fundamentais, tendo o ser humano como valor supremo de toda e qualquer proteção jurídica. A nova Lei de Migração trouxe maior efetividade na proteção dos refugiados e apátridas, que por vezes são vítimas do fenômeno do repúdio ao diferente e excluídos de toda e qualquer garantia jurídica dos Estados. Por meio da pesquisa bibliográfica e documental, com revisão da legislação e doutrina seguindo o método indutivo, os resultados obtidos foram no sentido de que o Decreto $n^{\circ}$ 9.199/17 que regulamentou a legislação brasileira de migração deu maior concretude ao preservar o princípio da dignidade da pessoa humana e o da fraternidade como um valor da solidariedade que se constitui como fundamento de uma sociedade fraterna e pluralista se constituindo em um importante instrumento normativa para a redução do número expressivo de apátridas no âmbito regional.

PALAVRAS-CHAVE: Nova lei de Migração; Apatridia; Dignidade da pessoa humana; Fraternidade; Direitos Humanos.

SUMÁRIO: Introdução. Os contornos jurídicos dos apátridas no Brasil. A fraternidade como diretriz de uma sociedade solidária. A dignidade da pessoa humana como valor supremo de uma sociedade fraterna, pluralista e sem preconceitos. Contextualizando a situação dos apátridas na nova lei de migração. Considerações finais. Referências.

\footnotetext{
${ }^{1}$ Pós-doutor em Direito pela Università degli Studi di Messina, Itália. Doutor em Direito pela UGF/RJ. Professor da Graduação e do PPGD - Mestrado e Doutorado em Proteção dos Direitos Fundamentais da Universidade de Itaúna (UIT) e das Faculdades Santo Agostinho (FASASETE). Universidade de Itaúna-MG (UIT) - Brasil. ORCID iD: http://orcid.org/0000-0001-7268-8009 URL: http://lattes.cnpq.br/1342540205762285 E-mail: deilton.ribeiro@terra.com.br ${ }^{2}$ Mestre em Direito pela Universidade de Itaúna-MG. Pós-graduada pela Universidade do Pará. Advogada. Universidade $\begin{array}{llllll}\text { de } & \text { Itaúna-MG } & \text { (UIT) } & - & \text { Brasil. } & \text { ORCID }\end{array}$ http://orcid.org/0000-0002-5360-3396 http://lattes.cnpq.br/5852107193399987 .E-mail: tatianemendesfaria@gmail.com
} 


\section{INTRODUÇÃO}

O presente trabalho visa analisar qual a contribuição da Lei $\mathrm{n}^{\circ} 13.445 / 17$, regulamentada pelo Decreto $n^{0}$ 9.199/17 acerca da apatridia, bem como a preocupação destes instrumentos em relação aos princípios da dignidade da pessoa humana e da fraternidade. Busca-se também averiguar se a maneira pela qual se pretendeu contribuir para a erradicação da apatridia, respeitou o ser humano e todos os direitos e garantias fundamentais a que fazem jus.

Sabe-se que são inúmeras as violações de direitos humanos perpetradas contra esse grupo de minoria, que muito embora seja extremamente expressivo, eis que segundo informações do Alto Comissariado das Nações Unidas para Refugiados (ACNUR) no mundo existe mais de 12 milhões de apátridas $^{3}$, número que pode se revelar ainda maior, justamente em razão da própria dificuldade de controle, ante a marginalização destas pessoas.

O reconhecimento de uma identidade e vinculação a um Estado é o direito básico de qualquer pessoa, eis que as demais garantias e direitos fundamentais só passam a ser tutelados a partir desta identificação.

O Brasil por meio da Emenda Constitucional n ${ }^{0}$ 54/07 deu nova redação à alínea c, do inciso I, do artigo 12 da Constituição Federal de $1988^{4}$, além de acrescentar o artigo 95 ao Ato das Disposições Constitucionais Transitórias, o que se revelou de suma importância, eis que ao alterar os critérios de concessão de nacionalidade o Brasil contribuiu para a redução dos apátridas.

Certo é que o Brasil vem se empenhando para auxiliar neste drástico problema de ausência de nacionalidade de milhares de pessoas no mundo. E nesse contexto foi muito bem recepcionada a Lei $\mathrm{n}^{\circ}$ 13.445/17. Entretanto, é preciso investigar se o Brasil se curva ao princípio da fraternidade como uma das vertentes da solidariedade, se de fato temos caminhado para uma sociedade fraterna e solidária. E muito além de solucionar o problema de garantia de nacionalidade da pessoa humana, é preciso averiguar se as condições e as garantias dadas a este grupo minoritário atenderam aos princípios da dignidade da pessoa humana e da fraternidade.

A nacionalidade passa pelo processo de reconhecimento e de autoidentidade da pessoa com o Estado, já que a ele se vinculará nas questões sociais, culturais e econômicas.

\footnotetext{
3 Informações do relatório da ACNUR de 2012.

${ }^{4}$ Artigo 12. São brasileiros: I - natos: c) os nascidos no estrangeiro, de pai brasileiro ou mãe brasileira, desde que venham a residir na República Federativa do Brasil e optem, em qualquer tempo, pela nacionalidade brasileira (Redação dada pela Emenda Constitucional de Revisão nº 03, de 1994).
} 
A dignidade da pessoa humana deve estar atrelada ao processo de respeito, liberdade e igualdade entre estas pessoas, vez que a imposição de uma definição de nacionalidade retrata a falta de liberdade e igualdade, revelando-se na mera negativa de direito.

Dessa forma, o tema problema da pesquisa é verificar se a Lei $n^{0} 13.445 / 17$ observa o princípio da dignidade da pessoa humana e se a fraternidade como um valor da solidariedade é igualmente, respeitada.

O artigo se divide em três partes: no primeiro item tem como temática central a definição dos apátridas, já no segundo momento discuti-se a conceituação dos princípios da dignidade da pessoa humana e da fraternidade, enquanto no último tópico realiza-se um confronto entre as determinações legais e os princípios norteadores do trabalho em questão. Como resultado final foi constatado que o Brasil inovou com a Lei $n^{\circ} 13.445 / 17$ e seu Decreto regulamentador, onde se buscou a manutenção do ideal de uma sociedade justa e fraterna e, muito além, de garantir a concretude do princípio da dignidade da pessoa humana.

Utilizou-se da pesquisa teórico-bibliográfica e documental, a partir do estudo de obras, artigos e diplomas legais sobre a temática, e, por meio do método indutivo, buscou-se estabelecer as premissas conceituais e práticas aplicadas na construção de uma política migratória para emigrantes no Brasil.

\section{OS CONTORNOS JURÍDICOS DOS APÁTRIDAS NO BRASIL}

O termo apatridia, que literalmente significa a ausência de uma pátria, muito provavelmente vem do francês apatridie, vocábulo que começou a ser utilizado pelos franceses apenas a partir da Primeira Guerra, em substituição aos termos alemães antes muitos difundidos: também chamada de Heimatlos, Heimatlosigkeit e, posteriormente, Staatslosigkeit. Preferiu-se também a fórmula sem pátria em oposição à opção italiana sem polis ou apolidia, já que a pátria havia há muito tempo superado os limites da polis (VICHNIAC, 1933, p. 134).

Tecnicamente, a apatridia significa a inexistência do vínculo jurídico de nacionalidade, ou seja, a ausência de conexão formal entre uma pessoa e um Estado qualquer. De forma resumida, esse vínculo de nacionalidade normalmente é adquirido já por ocasião do nascimento, seja em virtude da incidência do princípio do jus solis - atribuição da nacionalidade referente ao local do nascimento, seja do princípio do jus sanguinis - atribuição da nacionalidade dos genitores (LISOWSKI, 2012, p. 120).

O conceito de apátrida foi definido internacionalmente na Convenção sobre o Estatuto dos Apátridas de $1954^{5}$, ratificada pelo Brasil através do Decreto ${ }^{\circ} 4.246$ de 22 de maio de 2002.

\footnotetext{
${ }^{5}$ 1. Para os efeitos da presente Convenção, o termo apátrida designará toda pessoa que não seja considerada seu nacional por nenhum Estado, conforme sua legislação.
} 


\section{Quaestio Iuris}

vol. 12, nº.04, Riode Janeiro, 2019. pp. 2342

DOI: $10.12957 /$ rqi.2019.39548

Em outras palavras, o que define o apátrida é a ausência de vinculação de nacionalidade com qualquer Estado, ou seja, se exclui desse conceito a pessoa que por qualquer meio tenha condições de reconhecimento de nacionalidade por qualquer Estado. O que não significa dizer que um apátrida não possa ser um refugiado, tampouco o refugiado é necessariamente um apátrida. Segundo ACNUR (2012):

A stateless person may also be a refugee if he/she has been forced to leave his/her country of habitual residence because of persecution. Not all stateless persons are refugees, however, and many stateless persons never leave their country of residence. Similarly, some refugees may be stateless, but not all. ${ }^{6}$

Para Liliana Lyra Jubilut (2007, p. 122), “os apátridas são indivíduos desprovidos de nacionalidade e que, portanto, não contam com a proteção de nenhum Estado, sendo privados do exercício de qualquer direito".

A apatridia "possui várias causas, como a retirada por parte de um Estado de uma nacionalidade previamente existente ou a situação prática na qual, pelos critérios estabelecidos pelos Estados, o indivíduo não possui nenhuma nacionalidade" (JUBILUT, 2007, p.122-123).

Para Celso Lafer o número de apátridas se atrela, muitas vezes, às questões políticas:

O número de apátridas viu-se também multiplicado por uma prática política nova, fruto de atos do Estado no exercício da competência soberana em matéria de emigração, naturalização e nacionalidade. Refiro-me ao cancelamento em massa da nacionalidade por motivos políticos. Caminho inaugurado pelo governo soviético em 1921 em relação aos russos que viviam no estrangeiro sem passaportes das novas autoridades, ou que tinham abandonado a Rússia depois da Revolução sem autorização do governo soviético. Este caminho foi a seguir percorrido pelo nazismo, que promoveu desnacionalizações maciças, iniciadas por lei de 14 de julho de 1933, alcançando grande número de judeus e de imigrados políticos residentes fora do Reich (LAFER, 1999, p. 143).

De fato cabe ao Estado legislar acerca da aquisição da nacionalidade do seu território. "o princípio de nacionalidade significa um direito a autodeterminação nacional. De acordo com ele, toda nação que quer se governar a si própria tem direito a uma existência enquanto Estado independente" (BOBBIO, 1992, p.159).

Em decorrência das questões políticas, culturais e principalmente religiosas é que surgem as lacunas que ensejam a apatridia. Mas não é somente isso, esse poder soberano que possui o Estado, autoriza por vezes a discriminação, já que por meio da negativa da nacionalidade, surgem os apátridas.

\footnotetext{
${ }^{6}$ Um apátrida será também um refugiado, se fora compelido a deixar seu país de residência habitual, em virtude de uma perseguição. Nem todos os apátridas são refugiados, visto que, muitos apátridas nunca deixam seus países de residência. Igualmente, alguns refugiados possam ser apátridas, mas não todos (Tradução livre).
} 


\section{Quaestio Iuris}

vol.12,nº.04, Riode Janeiro, 2019. pp. 2342

DOI: $10.12957 /$ rqi.2019.39548

Não se pode olvidar que o direito a nacionalidade, muito embora se sujeite a soberania do Estado, é matéria de direito internacional, sendo, inclusive, prevista na Declaração Universal dos Direitos Humanos ${ }^{7}$. E mais, é o direito à nacionalidade o precursor de todos os demais direitos.

É justamente a partir da definição da nacionalidade, que se torna possível o exercício da cidadania, por meio da qual o cidadão poderá gozar dos direitos e deveres da nação à qual se vincular.

A Convenção sobre o Estatuto dos Apátridas de 1954 promulgada pelo Decreto $n^{\circ} 4.246,22$ de maio de 2002 mostra a preocupação a nível internacional sobre os apátridas e no seu texto já delineava as diretrizes para o tratamento destas pessoas, estabelecendo, portanto, alguns direitos aos apátridas residentes nos Estados contratantes, dentre eles:

Artigo 3 - Os Estados Contratantes aplicarão as disposições desta Convenção aos apátridas, sem discriminação por motivos de raça, religião ou país de origem.

Artigo 4 - Os Estados Contratantes garantirão aos apátridas em seu território um tratamento pelo menos tão favorável quanto o que garantem aos seus nacionais em relação à liberdade de praticar sua religião e no tocante à liberdade de instrução religiosa de seus filhos.

Artigo 13 - Os Estados Contratantes outorgarão a todo apátrida um tratamento tão favorável quanto possível e, em todo caso, não menos favorável que aquele concedido, nas mesmas circunstâncias, aos estrangeiros em geral, no que diz respeito à aquisição da propriedade móvel ou imóvel e aos direitos a elas relativos, ao aluguel e a outros contratos relativos à propriedade móvel e imóvel.

Artigo 16 - Todo apátrida gozará, no território dos Estados Contratantes, de livre e fácil acesso aos Tribunais (ACNUR, 1954), (BRASIL, 2002).

Dessa forma, em linhas gerais a Convenção pretendeu conferir de forma imediata alguns direitos aos apátridas, tais como a liberdade de religião, de circulação, o acesso à educação, o acesso aos tribunais e especialmente a igualdade de tratamento em relação aos estrangeiros. Mas é difícil imaginar que tais direitos sejam efetivados sem o apoio ou pelo menos a mediação dos Estados, que são os principais destinatários tanto do Estatuto dos Refugiados quanto do Estatuto dos apátridas. Isso significa dizer que, por mais que esses grupos humanos não estejam totalmente desamparados do ponto de vista do direito internacional, ainda não há uma forma mais efetiva de proteção do que a atribuição juridicamente formal de uma nacionalidade (LISOWSKI, 2012, p. 127).

A ausência de reconhecimento da nacionalidade resulta, em muitos casos, no deslocamento destas pessoas, o que atrai inúmeros problemas e de maneira globalizada. Não se trata de um problema isolado.

\footnotetext{
${ }^{7}$ Artigo XV - Toda pessoa tem direito a uma nacionalidade
} 


\section{Quaestio Iuris}

vol.12,nº.04, Riode Janeiro, 2019. pp. 2342

DOI: $10.12957 /$ rqi.2019.39548

A mesma política que nega o reconhecimento de nacional ao apátrida incentiva e fomenta a discriminação, autoriza o pensamento individual e mesquinho que se contrapõe ao princípio da fraternidade.

Os apátridas muitas das vezes se sujeitam a um Estado pouco preocupado com as questões humanitárias que difunde a ideia de que o apátrida não tem direitos, como se a filiação ou nascimento fosse escolha própria. Em razão das inúmeras possibilidades de apatridia, qualquer cidadão pode ficar sujeito à perda da nacionalidade.

A apatridia não decorre, tão somente, do nascimento, em muitos casos, a nacionalidade é perdida, como, por exemplo, no caso da extinta União Soviética ${ }^{8}$, talvez este motivo fosse o de maior relevância para que a apatridia fosse considerada um problema global e de todos.

A soberania nacional do Estado lhe confere o poder de definir a legislação nacional no que tange ao reconhecimento de quem são seus nacionais. E por mais que a Organização das Nações Unidas busque garantir os direitos humanos, incluindo ao invés de excluir as pessoas, estas questões só podem ser decididas internamente por cada país cabendo à sociedade civil a difusão, a luta e a busca por uma sociedade efetivamente fraterna.

Por esse motivo é que se entendeu necessária a adoção de medidas que, muito além de garantir alguns direitos aos apátridas, pudessem reduzir e prevenir a incidência de tais casos. Foi o que se pretendeu com a adoção, ainda no âmbito da Organização das Nações Unidas, da Convenção para a Redução dos casos de Apatridia de 1961.

Para Telma Rocha Lisowski (2012, p. 127-128) dois artigos dessa Convenção merecem destaque: o artigo $9^{\circ}$, segundo o qual "os Estados Contratantes não poderão privar qualquer pessoa ou grupo de pessoas de sua nacionalidade por motivos raciais, étnicos, religiosos ou políticos”, e o artigo 10, que dispõe,

1. Todo tratado entre os Estados Contratantes que dispuser sobre a transferência de território deverá incluir disposições para assegurar que os habitantes do referido território não se converterão em apátridas como resultado de tal transferência. Os Estados Contratantes se empenharão em assegurar que tais disposições figurem em todo tratado desse gênero realizado com um Estado que não seja Parte na presente Convenção.

2. Na ausência de tais disposições, o Estado Contratante ao qual tenha sido cedido um território ou que de outro modo haja adquirido um território atribuirá sua nacionalidade aos habitantes do referido território que de outro modo se tomariam apátridas como resultado da transferência ou aquisição de tal território.

\footnotetext{
${ }^{8}$ Um dos casos conhecidos: Quando a União Soviética chegou ao fim, em 1991, o agente de viagens Mikhail Sebastian virou apátrida. Nascido no Azerbaijão, na época em que o país ainda era parte da URSS, ele perdeu o direito à nacionalidade: o governo azerbaidjano não quis reconhecer Mikhail, pois ele pertencia à etnia armênia. A Armênia também não lhe deu cidadania, por não estar convencida de seus laços com o país (VIEIRA; GARATTONI, 2014).
} 
No âmbito regional, o artigo 20 do Pacto de São José da Costa Rica, que foi promulgado pelo Decreto $\mathrm{n}^{\circ}$ 678, de 06 de novembro de 1992 tem uma redação mais ampla do que aquela do artigo 15 da Declaração Universal dos Direitos Humanos no sentido de que "1. toda pessoa tem direito a uma nacionalidade. 2. Toda pessoa tem direito à nacionalidade do Estado em cujo território tiver nascido, se não tiver direito a outra. 3. A ninguém se deve privar arbitrariamente da sua nacionalidade nem do direito a mudá-la" (LISOWSKI, 2012, p. 128), (BRASIL, 1992).

\section{A FRATERNIDADE COMO DIRETRIZ DE UMA SOCIEDADE SOLIDÁRIA}

O Brasil adotou na Constituição Federal de 1988 uma sociedade fraterna, ao estabelecer em seu preâmbulo:

Nós, representantes do povo brasileiro, reunidos em Assembléia Nacional Constituinte, para instituir um Estado Democrático, destinado a assegurar o exercício dos direitos sociais e individuais, a liberdade, a segurança, o bem-estar, o desenvolvimento, a igualdade e a justiça como valores supremos de uma sociedade fraterna, pluralista e sem preconceitos, fundada na harmonia social e comprometida, na ordem interna e internacional, com a solução pacífica das controvérsias, promulgamos, sob a proteção de Deus, a seguinte Constituição da República Federativa do Brasil (O itálico é nosso).

Da mesma forma o artigo $3^{\circ}$, inciso I da Constituição Federal de 1988, constitui como objetivo fundamental da República Federativa do Brasil, a construção de uma sociedade livre, justa e solidária.

Assim, Deilton Ribeiro Brasil entende que,

O texto do preâmbulo revela que o Estado Democrático brasileiro instituído está destinado a assegurar o exercício dos direitos sociais e individuais e, considerá-los, como valores supremos de uma sociedade fraterna, pluralista e sem preconceitos, assim como a liberdade, a segurança, o bem-estar, o desenvolvimento, a igualdade e a justiça, devendo ser fundada na harmonia social e comprometida com a solução pacífica das controvérsias, tanto na ordem interna como, também, na ordem internacional (BRASIL, 2018, p. 760).

A solidariedade, assim como a fraternidade traz em seu âmago, a preocupação para com o outro, ou seja, a solidariedade que impõe que uma pessoa se preocupe com o outro e que cada um se preocupe com o todo, assim como a fraternidade, que traz a ideia de preocupação com o irmão, a união, exige uma responsabilidade do indivíduo para com a sociedade.

Aliás, a ideia da fraternidade foi lançada pós Revolução Francesa, que tinha como lema: liberdade; igualdade e fraternidade. Quando falamos sobre fraternidade, o primeiro pensamento é algo que se relaciona com a religião, que trata do cristianismo, normalmente temos a ideia de caridade em relação ao próximo. E talvez essa seja a concepção mais acertada, ter a fraternidade como a preocupação 


\section{Quaestio Iuris}

vol. 12, nº.04, Riode Janeiro, 2019.pp. 2342

DOI: $10.12957 /$ rqi.2019.39548

de ascensão e desenvolvimento humano, do próximo e de todos, uma coletividade unida para gozar e usufruir dos mesmos direitos e deveres.

Por sociedade fraterna, entende-se como um tipo de sociedade construída por "pessoas humanas estimuladas a perceber o sentido da própria existência e porque percebem o sentido da própria existência e, adotam modos de vida que dão sentido à existência do Humano e a sua continuidade no tempo e espaço da biosfera" (SILVA; BRANDÃO, 2015, p. 151).

A perspectiva da construção de uma sociedade fraterna global, pela concepção de um espaço público mundial, a partir de um projeto cultural que tenha por fundamento o sentido da existência do humano traz um grande e novo desafio à humanidade, que na organização da própria convivência terá que, antes de priorizar a reivindicação do caráter funcional, deverá priorizar a reivindicação do caráter humano, na qual o humano é o "sentido relacional de pensar e agir da pessoa humana" (SILVA; BRANDÃO, 2015, p. 151).

E não é por menos, que ao tratar do princípio da solidariedade, Daniel Sarmento se refere ao espaço de diálogo entre as pessoas dentro do Estado:

$\mathrm{Na}$ verdade, a solidariedade [aqui também é possível referir-se à fraternidade] implica reconhecimento de que, embora cada um de nós componha uma individualidade, irredutível ao todo, estamos também juntos, de alguma forma irmanados por um destino comum. Ela significa que a sociedade não deve ser um lócus da concorrência entre indivíduos isolados, perseguindo projetos pessoais antagônicos, mas sim um espaço de diálogo, cooperação e colaboração entre pessoas livres e iguais, que se reconheçam como tais (SARMENTO, 2006, p. 295).

O mundo globalizado, as concorrências, competitividades, falta de emprego, de saúde, educação, enfim, as situações de precariedade e o medo que assola o povo que deste mundo usufrui, incute nas pessoas a ideia de que o migrante, o refugiado, o apátrida são pessoas que querem, apenas, retirar do nacional as oportunidades de crescimento profissional e pessoal.

Para Zygmunt Bauman (1998) a minoria, o grupo de excluídos sofre as consequências como se dejetos fossem como se houvesse uma necessidade do planeta dejetar estas pessoas em algum lugar. E seu pensamento faz todo sentido pois a apatridia é uma questão mundial e cada vez mais os Estados querem se livrar de problemas, digo problemas porque aceitar um apátrida exige a concessão de direitos e garantias que passam pela responsabilidade do Estado. E crescentemente estas pessoas são tratadas como inimigas, como um ser estranho que precisa ser exterminado.

As relações interpessoais são influenciadas pela noção de solidariedade e cada membro da nação assume responsabilidades para com o outro. Tal princípio enfatiza a ajuda mútua que os membros de uma sociedade devem ter, definindo os mesmos direitos e deveres entre nacionais, naturalizados, apátridas.

A evolução da legislação brasileira é perceptível, o artigo 97 do Decreto 9.199/17 que 


\title{
Quaestio Iuris
}

regulamentou a Lei do migrante, não excluiu da possibilidade de proteção, nem mesmo os apátridas que por ventura tenham ingressado irregularmente no país 9

A solidariedade é verificada no plano fático e jurídico, as pessoas convivem no mesmo ambiente em razão da partilha de responsabilidades e direitos que são externados por meio de condutas objetivas que caracterizam a convivência social. O ambiente social, o Estado, deve ser um lugar de colaboração, cooperação e assistência. Para Chiara Lubich (2003, p. 309-310):

\begin{abstract}
A fraternidade é um empenho que: favorece o desenvolvimento autenticamente humano do país sem isolar na incerteza do futuro as categorias mais facas, sem excluir outras do bem-estar, sem criar novas pobrezas; salvaguarda os direitos da cidadania e o acesso à própria cidadania, abrindo uma esperança a todos que buscam a possibilidade de uma vida digna em nosso país, o qual pode mostrar a própria grandeza oferecendo-se como pátria para quem perdeu, ajuda a pesquisa científica e a invenção de novas tecnologias, salvaguardando, ao mesmo tempo, a dignidade da pessoa humana do primeiro ao último instante de sua vida fornecendo sempre as condições para que cada pessoa possa exercer a própria liberdade de escolha e possa crescer assumindo responsabilidades.
\end{abstract}

Por óbvio, que para se admitir e conceber a ideia de uma sociedade fraterna, solidária, e via de consequência justa, é preciso respeitar o indivíduo na sua essência é preciso zelar pela efetividade da dignidade da pessoa humana. Possibilitando ao cidadão apátrida o direito de se autoidentificar, de se reconhecer e de se filiar a valores culturais, históricos, religiosos e sociais, com os quais se identifica.

Para Resta; Jaborandy; Martini (2017, p. 94) "é evidente que entre a dignidade e a ideia de comunidade humana existe um nexo causal inseparável", daí porque não se pode dissociar a ideia de fraternidade da ideia de dignidade da pessoa humana.

\section{A DIGNIDADE DA PESSOA HUMANA COMO VALOR SUPREMO DE UMA SOCIEDADE FRATERNA, PLURALISTA E SEM PRECONCEITOS}

O princípio da dignidade da pessoa humana, previsto no artigo $1^{\circ}$, III, da Constituição Federal de 1988 e é um dos fundamentos da República Federativa do Brasil (BRASIL, 1988).

Conforme as relações globais evoluem e se dinamizam, os dispositivos normativos devem sempre se orientar pela dignidade da pessoa a fim de que todos os direitos inerentes à condição humana daqueles envolvidos nas relações entre cidadãos e Estado sejam tutelados e efetivamente assegurados.

Como um valor fundamental que é também um princípio constitucional, a dignidade humana

\footnotetext{
${ }^{9}$ Artigo 97. O ingresso irregular no território nacional não constitui impedimento para a solicitação de reconhecimento da condição de apátrida e para a aplicação dos mecanismos de proteção da pessoa apátrida e de redução da apatridia, hipótese em que não incidirá o disposto no artigo 307, desde que, ao final do procedimento, a condição de apátrida seja reconhecida.
} 


\section{Quaestio Iuris}

vol. 12, nº.04, Riode Janeiro, 2019. pp. 2342

DOI: $10.12957 /$ rqi.2019.39548

funciona tanto como justificação moral quanto como fundamento jurídico-normativo dos direitos fundamentais. Sendo assim, ela vai necessariamente informar a interpretação de tais direitos constitucionais ajudando a definir o seu sentido nos casos concretos. Além disso, nos casos envolvendo lacunas no ordenamento jurídico, ambigüidades no direito, colisões entre direitos fundamentais e tensões entre direitos e metas coletivas, a dignidade humana pode ser uma bússola na busca da melhor solução. Mais ainda, qualquer lei que viole a dignidade, seja em abstrato ou em concreto, será nula (BARROSO, 2016, p. 64-66).

Melhor explicando, o princípio da dignidade humana é a qualidade intrínseca e distintiva reconhecida em cada ser humano que o faz merecedor do mesmo respeito e consideração por parte do Estado e da comunidade, implicando, neste sentido, um complexo de direitos e deveres fundamentais que assegurem a pessoa tanto contra todo e qualquer ato de cunho degradante e desumano, como venham a lhe garantir as condições existenciais mínimas para uma vida saudável, além de propiciar e promover sua participação ativa e corresponsável nos destinos da própria existência da vida em comunhão com os demais seres humanos (SARLET, 2008, p. 63).

A autonomia é o elemento ético da dignidade humana. É o fundamento do livre arbítrio dos indivíduos, que lhes permite buscar, da sua própria maneira, o ideal de viver bem e de ter uma vida boa. A noção central aqui é a de autodeterminação: uma pessoa autônoma define as regras que vão reger a sua vida. A autonomia pressupõe o preenchimento de determinadas condições, como a razão (a capacidade mental de tomar decisões informadas), a independência (a ausência de coerção, de manipulação e de privações essenciais) e a escolha (a existência real de alternativas). A autonomia, portanto, corresponde à capacidade de alguém tomar decisões e de fazer escolhas pessoais ao longo da vida, baseadas na sua própria concepção de bem, sem influências externas indevidas. Quanto às suas implicações jurídicas, a autonomia está subjacente a um conjunto de direitos fundamentais associados com o constitucionalismo democrático, incluindo as liberdades básicas (autonomia privada) e o direito à participação política (autonomia pública). Por fim, ínsito à ideia de dignidade humana está o conceito de mínimo existencial, também chamado de mínimo social, ou o direito básico às provisões necessárias para que se viva dignamente (BARROSO, 2016, p. 81-85).

Assim, os princípios fundamentais são concretizações ou exteriorização do princípio da dignidade humana, pois onde não houver respeito pela vida e pela integridade física e moral do ser humano, onde as condições mínimas para uma existência digna não forem asseguradas, onde não houver limitação do poder, enfim, onde a liberdade e a autonomia, a igualdade (em direitos e dignidade) e os direitos fundamentais não forem reconhecidos e minimamente assegurados, não haverá espaço para a dignidade humana e esta (a pessoa), por sua vez, poderá não passar de mero objeto de arbítrio e injustiças (SARLET, 2008, p. 59). 


\section{Quaestio Iuris}

vol. 12, nº.04, Riode Janeiro, 2019. pp. 2342

DOI: $10.12957 /$ rqi.2019.39548

Dessa forma, o princípio em questão traduz uma noção fundamental de respeito à pessoa humana, aludindo que respeitar essa condição humanística é imprescindível para a realização pessoal, revelando que o direito ao livre desenvolvimento da personalidade deve ser promovido por meio de ações estatais que confiram ao indivíduo a liberdade de estabelecer o seu ideal de vida digna, traçando objetivos e valores a serem concretizados.

Para Flávia Piovesan,

A dignidade da pessoa humana é princípio que unifica e centraliza todo o sistema normativo, assumindo especial prioridade. A dignidade da pessoa humana simboliza, deste modo, verdadeiro super princípio constitucional, a norma maior a orientar o constitucionalismo contemporâneo, nas esferas local e global, dotando-lhe de especial racionalidade, unidade e sentido (PIOVESAN, 2004, p. 79-100)

A concretude da dignidade da pessoa humana, valor máximo e fundamental dos Direitos Humanos, apenas ocorrerá em uma sociedade considerada fraterna, em que há o respeito ao próximo e convivência harmônica para reger as relações entre os indivíduos. Em outras palavras, essa fraternidade deve ser compreendida como uma virtude da cidadania, que supera as fronteiras da pátria ou da nação (cidadania interna), numa perspectiva universal de pessoa humana (cidadania global), reivindicando o sentido da existência do humano e a sua continuidade no tempo e espaço (MACHADO, 2013, p. 79).

Assim, para se alcançar a dignidade é preciso fomentar o livre desenvolvimento da personalidade que decorre de preceitos constitucionais que propiciam um sistema jurídico que viabiliza ao indivíduo a liberdade de ser e viver do modo como o realiza, o que, muitas das vezes, pode não coincidir com os padrões e modelos impostos pelo Estado que reconhece o apátrida.

\section{CONTEXTUALIZANDO A SITUAÇÃO DOS APÁTRIDAS NA NOVA LEI DE MIGRAÇÃO}

A Lei de Migração Brasileira foi publicada em 24 de maio de 2017, entrou em vigor somente em novembro de 2017, regulamentada pelo Decreto ${ }^{\circ} 9.199$ de 20 de novembro de 2017. A Lei $n^{\circ} 13.445$ revogou o Estatuto do Estrangeiro - Lei nº 6.815/1980, ao assumir, no ordenamento jurídico brasileiro, uma postura positiva em relação a esta normativa.

A nova Lei de Migração pode ser considerada como um avanço no campo dos direitos humanos e da política migratória brasileira (...) seu texto mostra o interesse da reversão de pontos arenosos, como a personalidade militarista ainda identificável no Estatuto do Estrangeiro. Reflete um movimento de atualização e de aproximação às pautas de direitos e questões humanitárias mundialmente consolidadas. A partir do próprio título comum, a nova lei sinaliza os seus interesses a partir de uma própria e interna renovação conceitual: não mais se refere ao estrangeiro, mas sim ao termo imigrante (AMARAL; COSTA; ALLGAYER, 2017, p. 270). 


\section{Quaestio Iuris}

A Lei $n^{0} 13.445 / 2017$, diferentemente da lei de 1980, sob um viés de efetividade de direitos humanos, passou a considerar o migrante como sujeito de direitos e deveres, em condição de igualdade com os nacionais. A ele foram conferidos direitos fundamentais assegurados pela Constituição Federal de 1988, sobretudo direito à inviolabilidade do direito à vida, liberdade, igualdade, segurança e propriedade. Assegura, ainda, dentre outros direitos, o acesso do migrante a serviços públicos de saúde, assistência e previdência sociais, bem como a aplicação de normas de proteção ao trabalhador (BRASIL, 2017).

São destinatários da Lei $\mathrm{n}^{\circ}$ 13.445/2017 os migrantes - que envolvem os imigrantes, emigrantes e apátridas ${ }^{10}$ - os visitantes e os residentes fronteiriços.

Assim como a história de acolhimento migratório brasileiro é significativa, a presença dos brasileiros pelo mundo apresenta uma questão quantitativa de vulto. No reconhecimento da problemática desses cidadãos em sua acolhida em diversos países e em busca de uma reciprocidade positiva, a Nova Lei de Migração procura consolidar uma cultura de acolhimento (AMARAL; COSTA; ALLGAYER, 2017, p. 270).

Partindo da premissa de que o apátrida busca o direito de ter direitos, não se pode coadunar com a imposição da nacionalidade. E nesse sentido a Lei n ${ }^{\circ}$ 13.445/17 caminhou muito bem, já que concedeu ao apátrida o direito de se reconhecer ou não como nacional.

Por seu turno, o artigo 26 da Lei $n^{\circ} 13.445 / 17$ assim dispõe:

Artigo 26. Regulamento disporá sobre instituto protetivo especial do apátrida, consolidado em processo simplificado de naturalização.

$\S 5^{\circ} \mathrm{O}$ processo de reconhecimento da condição de apátrida tem como objetivo verificar se o solicitante é considerado nacional pela legislação de algum Estado e poderá considerar informações, documentos e declarações prestadas pelo próprio solicitante e por órgãos e organismos nacionais e internacionais.

$\S 6^{\circ}$ Reconhecida a condição de apátrida, nos termos do inciso VI do $\S 1$ o do artigo $1^{\circ}$, o solicitante será consultado sobre o desejo de adquirir a nacionalidade brasileira.

$\S 7^{\circ}$ Caso o apátrida opte pela naturalização, a decisão sobre o reconhecimento será encaminhada ao órgão competente do Poder Executivo para publicação dos atos necessários à efetivação da naturalização no prazo de 30 (trinta) dias, observado o artigo 65 .

É possível perceber que a lei não impôs ao apátrida o reconhecimento da cidadania brasileira. Da leitura do parágrafo $5^{\circ}$, do artigo 26 é possível perceber que deve haver uma solicitação do apátrida, e

\footnotetext{
${ }^{10}$ Decreto ${ }^{\circ}$ 9.199/2017, Artigo 1º, Parágrafo único. Para fins do disposto na Lei $\mathrm{n}^{\circ}$ 13.445, de 2017, consideram-se: I migrante - pessoa que se desloque de país ou região geográfica ao território de outro país ou região geográfica, em que estão incluídos o imigrante, o emigrante e o apátrida; (...)
} 
que sendo reconhecida esta condição, o solicitante será consultado sobre o seu interesse de se tornar um cidadão brasileiro.

O Decreto $n^{0}$ 9.199/17 que regulamentou esta lei não destoou desta previsão, repetiu em seu artigo 96, a previsão de que o reconhecimento da condição de apátrida deve ser requerido, não pairando dúvidas:

Artigo 96. O processo de reconhecimento da condição de apátrida tem como objetivo verificar se o solicitante é considerado nacional pela legislação de algum Estado e poderá considerar informações, documentos e declarações prestadas pelo próprio solicitante e por órgãos e organismos nacionais e internacionais.

$\S 2^{\circ} \mathrm{O}$ processo de reconhecimento da condição de apátrida será iniciado por meio da solicitação do interessado apresentada ao Ministério da Justiça e Segurança Pública ou às unidades da Polícia Federal (O itálico é nosso).

Possibilitar ao apátrida o direito de ser reconhecido ou não como brasileiro é de grande valia para o princípio da dignidade da pessoa humana, já que possibilita a estas pessoas o direito de compartilhar dos direitos e deveres impostos internamente. A cultura é fator importante na construção e no desenvolvimento da personalidade e, garante ao cidadão o direito de liberdade e igualdade.

$\mathrm{O}$ direito geral de personalidade tem como escopo a proteção da personalidade humana e manifesta uma cláusula geral de tutela da pessoa humana, já que proporciona o acolhimento de novos direitos, desde que haja respeito à dignidade, Ingo Sarlet pontua que "o objeto deste direito abrangeria a todas as manifestações atuais e futuras, previsíveis e imprevisíveis, tutelando a sua livre realização e desenvolvimento, sendo o princípio superior de constituição dos direitos que se referem a particulares modo de ser da personalidade" (SARLET, 2008, p. 68).

A constatação do direito geral de personalidade é fundamento especifico para materialização de uma tutela ao direito ao livre desenvolvimento da personalidade, José Joaquim Gomes Canotilho (2003, p. 405) preleciona que "tendo em vista que os direitos fundamentais cada vez mais tendem a ser direitos de personalidade e de uma concepção geral de direito de personalidade, automatizou-se um direito ao desenvolvimento da personalidade".

O direito ao livre desenvolvimento da personalidade decorre da dignidade da pessoa humana, como afirmação positiva desta, “decorre não só da dignidade da pessoa humana, mas também de um direito geral de liberdade" (SARLET, 2008, p.100). Todo ordenamento jurídico que busca fundamento na dignidade humana garante o desenvolvimento da personalidade.

A Declaração Universal de Direitos Humanos de 1948 traz expressa previsão acerca desse direito, é o que se verifica nos artigos 22, 26 e 29, a seguir:

Artigo 22. Todo ser humano, como membro da sociedade, tem direito à segurança social e à realização, pelo esforço nacional, pela cooperação internacional e de acordo com a 
organização e recursos de cada Estado, dos direitos econômicos, sociais e culturais indispensáveis à sua dignidade e ao livre desenvolvimento da sua personalidade. (...)

Artigo 26. 1. Todo ser humano tem direito à instrução. A instrução será gratuita, pelo menos nos graus elementares e fundamentais.(...) 2. A instrução será orientada no sentido do pleno desenvolvimento da personalidade humana e do fortalecimento do respeito pelos direitos humanos e pelas liberdades fundamentais. (...)

Artigo 29. 1. Todo ser humano tem deveres para com a comunidade, em que o livre e pleno desenvolvimento de sua personalidade é possível (ONU, 1948).

Valério de Oliveira Mazzuoli (2014) assim conceitua:

Os direitos humanos são, portanto, direitos protegidos pela ordem internacional(especialmente por meio de tratados multilaterais, globais ou regionais) contra as violações e arbitrariedades que um Estado possa cometer às pessoas sujeitas à sua jurisdição. São direitos que estabelecem um nível protetivo (standard) mínimo que todos os Estados devem respeitar, sob pena de responsabilidade internacional. Assim sendo, garantem às pessoas sujeitas à jurisdição do Estado meios de vindicação de seus direitos, para além do plano interno, nas instâncias internacionais de proteção.

Esses direitos são aqueles essenciais para que o homem possa sobreviver de forma digna. "São aqueles dos quais o ser humano é titular em função de uma construção histórica que buscou assegurar proteção à dignidade humana, característica inerente aos seres humanos, e que todos possuem simplesmente por serem humanos" (JUBILUT, 2007, p. 51).

Fábio Konder Comparato (2001, p. 01) aponta como base dos direitos humanos o fato de que:

Todos os seres humanos, apesar das inúmeras diferenças biológicas e culturais que os distinguem entre si, merecem igual respeito, como únicos entes no mundo capazes de amar, descobrir a verdade e criar a beleza. É o reconhecimento universal de que, em razão dessa radical igualdade, ninguém - nenhum indivíduo, gênero, etnia, classe social, grupo religioso ou nação - pode afirmar-se superior aos demais.

Na Constituição Federal de 1988 não se encontra dispositivo expresso acerca do direito ao desenvolvimento da personalidade, contudo o reconhecimento decorre do parágrafo segundo do artigo quinto da Constituição Brasileira ao prevê a cláusula aberta, bem como em razão do regime e dos princípios adotados pelo sistema jurídico.

A partir dessas proposições Ingo Sarlet (2008, p. 100-101) entende que "o direito ao livre desenvolvimento da liberdade ou ao direito geral de personalidade é direito implícito na ordem jurídica brasileira e pressuposto para uma cláusula geral de tutela da personalidade”.

Trata-se de um direito de agir que não sofre interferência ou impedimentos, garante a autonomia e autodeterminação do sujeito, dede que haja respeito à dignidade humana. É de se notar que tratando a todos com igual respeito e consideração garante-se o direito à formação livre da personalidade ou 


\section{Quaestio Iuris}

vol. 12, nº.04, Riode Janeiro, 2019. pp. 2342

DOI: $10.12957 /$ rqi.2019.39548

liberdade de ação como sujeito autônomo e dotado de autodeterminação decisória, permitindo que cada um edifique sua personalidade conforme lhe convier. E porque não dizer que esta seria a grande busca do apátrida, o direito a ter direitos.

Dessa concepção decorre o fato de cada um tem o direito e liberdade de se constituir cidadão, a partir do modelo que bem atenda aos seus anseios e à proteção do seu entendimento de dignidade.

Hannah Arendt (2007, p. 333) ainda ressalta que os direitos humanos pressupõem a cidadania como um princípio, pois a privação da mesma repercute na condição humana, isto porque o ser humano privado de proteção conferida por um estatuto político esvazia-se da sua substância de ser tratado pelos outros como semelhante. Dessa forma, destaca-se que o primeiro direito humano é o direito a ter direitos, o que só é possível mediante o pertencimento, pelo vínculo de cidadania, a algum tipo de comunidade juridicamente organizada e ser tratado dentro dos parâmetros definidos pelos princípios da legalidade.

Dessa forma, a noção do direito a ter direitos apenas pode ser compreendida a partir de espaçostempos próprios. Por isso, a afirmação de categorias estanques em se tratando da imigração é, de fato, uma violência, por vezes ostensiva na criminalização de alguns fluxos. Esse espaço-tempo próprio revela a constituição de um sujeito coletivo e de um espaço público, cuja subjetividade pressupõe a possibilidade de participação nesse espaço (REDIN, 2010, p. 50).

\section{CONSIDERAÇÕES FINAIS}

Há muito o ACNUR tem desempenhado um papel importante na instauração de uma sociedade mais fraterna e justa. Suas convenções e recomendações insistem na garantia dos direitos humanos, porém em razão da soberania dos Estados que permite a decisão acerca da definição de quem são seus nacionais, o problema continua a se multiplicar pelo mundo, sem uma resposta imediata.

O que se constata é que o Brasil tem cumprido com o seu papel humanitário, ao criar legislação que concede nacionalidade aos apátridas residentes em seu território. Além disso, a legislação consoante se verificou, teve o cuidado de garantir ao apátrida a escolha pela nacionalidade brasileira, o que demonstra o cuidado com o desenvolvimento do ser humano.

A nacionalidade traz consequências para a vida do ser humano, já que impõe ao cidadão a aceitação das regras internas. Se por um lado o apátrida passa a usufruir dos direitos e garantias do Brasil, por outro se obriga a sua legislação também em relação aos deveres.

Para se alcançar a dignidade é preciso respeito às crenças, culturas e história da pessoa humana, em razão disso é indispensável que o apátrida tenha identidade com a nação que o acolheu, porque do contrário, teríamos uma imposição, o que poderia força-lo a refugiar-se, retirar-se do país que o naturalizou, transferindo o problema para o próximo e esvaindo-se da ideia de fraternidade. 
Se a dignidade da pessoa humana exige o respeito para o desenvolvimento humano, a fraternidade deve ser pensada ao ponto de incluir o próximo com as suas diferenças, com o seu estilo de vida cultural, social, ideológico.

A intolerância não caminha com o princípio da fraternidade, acolher o outro deve ser uma atividade de aceitação do ser individual, é preciso saber de onde vem e para onde vai, mas muito além, quem é a pessoa acolhida, as suas escolhas e o seu modo de ser e enxergar a vida, é o exercício diário da liberdade e da igualdade, a liberdade pelas escolhas e a igualdade em relação àquele que tem a liberdade de ser e exercer o que quiser.

O legislador brasileiro ao implantar a Lei $n^{\circ} 13.445 / 17$ e o Decreto $n^{\circ} 9.199 / 17$ atendeu as recomendações internacionais e efetivamente contribuiu para a tutela dos direitos humanos e fundamentais, observando os princípios da fraternidade e da dignidade da pessoa humana. Isso não significa que o seu papel se esgotou, há muito a ser feito, a contribuição se deu por meio de normas que na prática ainda precisa ser acompanhada, principalmente nesse momento de transição de Governo, onde as políticas migratórias podem ser distintas. Aliás, a própria retirada do Brasil do Pacto Global de Migração da ONU, sinaliza uma realidade distinta do que se viu no papel. A legislação é favorável, porém para que seja aplaudida é preciso que ela efetivamente seja cumprida, não se pode permitir que se torne letra morta.

O Brasil precisa incentivar a cultura da fraternidade, o respeito ao próximo e ao vulnerável, é preciso acolher a minoria. Não podemos mais aceitar o descarte do diferente, ignorar os apátridas como se não fossem seres humanos, lutar pelo direito de ter direitos é uma tarefa árdua e precisa do envolvimento de toda a sociedade. É preciso lembrar que o cidadão apátrida naturalizado não recebe somente direitos, recebe deveres, é preciso acreditar que cada ser humano traz contribuições para a sociedade.

\title{
THE SITUATION OF STATELESS PERSONS IN THE NEW BRAZILIAN MIGRATION ACT: DIALOGUES WITH THE HUMAN DIGNITY AND BROTHERHOOD PRINCIPLES
}

\begin{abstract}
:
The aim of this paper is to analyze the legal status of stateless persons in the face of 13,455/17 Act while investigating the effective contribution to the guarantee of fundamental rights, with the human being as the supreme value of any and all legal protection. The new Migration Act brought greater effectiveness in the protection of refugees and stateless persons, who are sometimes victims of the phenomenon of rejection of the unlike and those who are out from any legal guarantee of the States. Through the bibliographical and documentary research, with a review of the legislation and doctrine following the inductive method, the research results obtained were that 9,199/17 Decree, which regulated the Brazilian
\end{abstract}


migration legislation, gave concreteness in preserving the principle of the dignity of the person and that of the brotherhood as a value of solidarity that is the foundation of a fraternal and pluralistic society, constituting as an important normative instrument for the reduction of the expressive number of stateless persons in the regional level.

KEYWORDS: New Migration Act; Statelessness; Dignity of human person; Brotherhood; Human rights.

\section{REFERÊNCIAS}

ACNUR. Convenção sobre o estatuto dos apátridas. Disponível em:

http://www.acnur.org/fileadmin/Documentos/portugues/BDL/Convencao_sobre_o_Estatuto_dos_Apatri das_de_1954.pdf. Acesso em 19 jan. 2019.

ACNUR. Convenção para a redução dos casos de apatridia de 1961. Disponível em:

http://www.acnur.org/fileadmin/Documentos/portugues/BDL/Convencao_para_a_Reducao_dos_Casos_ de_Apatridia_de_1961.pdf. Acesso em: 20 jan. 2019.

ACNUR. Em busca de uma nacionalidade. Disponível em: http://www.acnur.org/portugues/quemajudamos/apatridas/. Acesso em: 11 jan. 2019.

ACNUR. What would life be like if you had no nationality? Disponível em: http://www.unhcr.org/3b8f92124.pdf. Acesso em: 11 jan. 2019.

ACNUR. Agência da ONU para refugiados. Disponível em: http://www.acnur.org/portugues/acnurno-brasil/. Acesso em: 11 jan. 2019.

AMARAL, Ana Paula Martins; COSTA, Luiz Rosado; ALLGAYER, Cristiane Batista Arrua. O brasileiro como estrangeiro: a política migratória brasileira para emigrantes. Cadernos de Direito, Piracicaba, v. 17(33): 257-285, jul.-dez. 2017. Disponível em:

http://www.metodista.br/revistas/revistas-unimep/index.php/cd/article/view/3565/2097. Acesso em: 10 jan. 2019.

ARENDT, Hannah. A condição humana. Tradução de Roberto Raposo, pósfacio de Celso Lafer. 10. ed. Rio de Janeiro: Forense Universitária, 2007.

BAGGIO, Antônio Maria et al. O princípio esquecido. São Paulo: Editora Cidade Nova, 2008.

BARROSO, Luís Roberto. A dignidade da pessoa humana no direito constitucional

contemporâneo: a construção de um conceito jurídico à luz da jurisprudência mundial. 4. reimpressão. Belo Horizonte: Editora Fórum, 2016.

BAUMAN, Zygmunt. O mal estar na pós-modernidade. Rio de Janeiro: Zahar, 1998.

BOBBIO, Norberto. A era dos direitos. Rio de Janeiro: Campus, 1992.

BRASIL, Deilton Ribeiro. As dimensões políticas, sociais e econômicas da nova lei de migração e os direitos humanos em uma sociedade globalizada. Revista Argumentum. v. 19, n. 3, 2018. p. 757-774. 
Disponível em: http://ojs.unimar.br/index.php/revistaargumentum/article/view/573. Acesso em: 03 jan. 2019

BRASIL. Constituição Federal. Constituição da República Federativa do Brasil de 1988. Publicada no Diário Oficial da União, Brasília, 05 out. 1988. Disponível em:

http://www.planalto.gov.br/ccivil_03/constituicao/constituicaocompilado.htm. Acesso em: 11 jan. 2019.

BRASIL. Decreto n ${ }^{\circ}$ 678, de 06 de novembro de 1992. Promulga a Convenção Americana sobre Direitos Humanos (Pacto de São José da Costa Rica), de 22 de novembro de 1969. Publicado no Diário Oficial da União, Brasília, 09 nov. 1992. Disponível em:

http://www.planalto.gov.br/ccivil_03/decreto/D0678.htm. Acesso em: 20 jan. 2019.

BRASIL. Decreto $n^{\circ} 4.246$, de 22 de maio de 2002. Promulga a Convenção sobre o Estatuto dos Apátridas. Publicado no Diário Oficial da União, Brasília, 23 maio 2002. Disponível em: http://www.planalto.gov.br/ccivil_03/decreto/2002/D4246.htm. Acesso em: 19 jan. 2019.

BRASIL. Decreto $n^{\circ} 9.199$, de 20 de novembro de 2017. Regulamenta a Lei $n^{\circ} 13.445$, de 24 de maio de 2017, que institui a Lei de Migração. Publicado no Diário Oficial da União, Brasília, 21 nov. 2017. Disponível em: http://www.planalto.gov.br/ccivil_03/_ato2015-2018/2017/decreto/D9199.htm. Acesso em 12 jan. 2019.

BRASIL. Lei n ${ }^{\circ}$ 13.445, de 24 de maio de 2017. Institui a Lei de Migração. Publicado no Diário Oficial da União, Brasília, 25 maio 2017. Disponível em: http://www.planalto.gov.br/ccivil_03/_ato20152018/2017/lei/L13445.htm. Acesso em 23 dez. 2017.

CANOTILHO, José Joaquim Gomes. Direito constitucional e teoria da constituição. 7. ed. Coimbra: Almedina, 2003.

CIDH. Convenção Americana sobre Direitos Humanos (Pacto de São José da Costa Rica), de 22 de novembro de 1969. Disponível em: http://www.cidh.oas.org/basicos/portugues/c.convencao_americana.htm. Acesso em: 20 jan. 2019.

COMPARATO. Fábio Konder. A afirmação histórica dos direitos humanos. 2. ed. São Paulo: Saraiva, 2001.

HABERMAS, Jürgen. A inclusão do outro: estudos de teoria política. Tradução de George Sperber; Paulo Astor Soethe (UFPR). São Paulo: Edições Loyola, 2002.

JUBILUT, Liliana Lyra $\mathbf{O}$ direito internacional dos refugiados e sua aplicação no orçamento jurídico brasileiro. São Paulo: Método, 2007.

LAFER, Celso. A reconstrução dos direitos humanos: um diálogo com o pensamento de Hannah Arendt. São Paulo: Companhia das Letras, 1999.

LISOWSKI, Telma Rocha. A apatridia e o "Direito a ter Direitos": um estudo sobre o histórico e o estatuto jurídico dos apátridas. In: Revista Jurídica da Procuradoria Geral do Estado do Paraná, Curitiba, $n^{\circ}$ 03, p. 109-134, 2012.

LUBICH, Chiara. Ideal e luz. Pensamento, Espiritualidade e Mundo Unido. São Paulo: Cidade Nova, 2003. 
MACHADO, Carlos Augusto Alcântara. A fraternidade e o direito constitucional brasileiro: anotações sobre a incidência e aplicabilidade do princípio/valor fraternidade no direito constitucional brasileiro a partir da sua referência no preâmbulo da Constituição federal de 1988. In: PIERRE, Luiz A. A. et al [Org.]. A fraternidade como categoria jurídica. São Paulo: Cidade Nova, 2013.

MAURER, Béatrice. Notas sobre o respeito da dignidade da pessoa humana ou pequena fuga incompleta em torno de um tema central. In: Dimensões da dignidade: ensaios de Filosofia do Direito e Direito Constitucional. 2 ed. Porto Alegre: Livraria do Advogado Editora, 2013.

MAZZUOLI, Valério de Oliveira. Curso de direitos humanos. São Paulo: Método, 2014.

MOREIRA, Marcele de Almeida Lima. Apátridas: a efetivação dos direitos fundamentais dos apátridas sob a tutela da Organização das Nações Unidas. Brasília: UniCEUB, 2011.

ONU. Declaração Universal dos Direitos Humanos de 1948. Disponível em:

http://www.unicef.org/brazil/pt/resources_10133.html. Acesso em: 19 jan. 2019.

PIOVESAN, Flávia. Direitos Humanos, o princípio da dignidade humana e a Constituição Brasileira de 1988. In: Revista do Instituto de Hermenêutica Jurídica - (Neo) Constitucionalismo: ontem, os códigos, hoje as Constituições. Porto Alegre: Instituto de Hermenêutica Jurídica, 2004, p. 79-100. REDIN, Giuliana. Direito de imigrar: direitos humanos e espaço público na sociedade contemporânea. 2010. 197 f. Tese (Programa de Pós-Graduação strictu sensu em Direito da Pontifícia Universidade Católica do Paraná), Curitiba, 2010. Disponível em: http://www.biblioteca.pucpr.br/pergamum/biblioteca/img.php?arquivo=/000051/0000512f.pdf. Acesso em: 19 jan. 2019.

RESTA, Eligio. Direito fraterno. Tradução de Sandra Regina Martini Vial. Santa Cruz do Sul: EDUNISC, 2004.

RESTA, Eligio; JABORANDY, Clara Cardoso Machado; MARTINI, Sandra Regina. Direito e fraternidade: a dignidade humana como fundamento. In: Revista do Direito. Santa Cruz do Sul, v. 3, n. 53, p. 92-103, set./dez. 2017. Disponível em:

http://online.unisc.br/seer/index.php/direito/article/view/11364/6967. Acesso: 11 jan. 2019.

\section{SARLET, Ingo Wolfgang. Dignidade da pessoa humana e direitos fundamentais na Constituição}

Federal de 1988. 6 ed. Porto Alegre: Livraria do Advogado, 2008.

SARMENTO, Daniel. Direitos fundamentais e relações privadas. Rio de Janeiro: Lumen Juris, 2006.

SILVA, Ildete Regina Vale da; BRANDÃO, Paulo de Tarso. Constituição e fraternidade: o valor normativo do Preâmbulo da Constituição. Curitiba: Juruá, 2015.

VICHNIAC, Marc. Le Statut International des Apatrides. In: Recueil des cours, Académie de droit international de La Haye, v. 43, p. 119-245, 1933.

VIEIRA, Vanessa; GARATTONI, Bruno. As pessoas de lugar nenhum. In: Revista Super Interessante, edição $n^{\circ}$ 156, São Paulo: Abril Cultural, set.-2014. Disponível em: http://super.abril.com.br/historia/apatridas-as-pessoas-de-lugar-nenhum/. Acesso em: 14 jan. 2019. 
Quaestio Iuris

vol. 12, n .04 , Riode Janeiro, 2019. pp. 2342 DOI: 10.12957/rqi.2019.39548

Trabalho enviado em 20 de janeiro de 2019

Aceito em 06 de fevereiro de 2020 